\title{
A Formalized Assessment of the Scenario Development of the National Economy in the Context of the Penetration of Blockchain Technologies Into the Financial Sector of Transactions
}

\author{
Marat Rashitovich Safiullin ${ }^{1}$, Leonid Alekseevich Elshin ${ }^{2}$, Alia Aidarovna Abdukaeva ${ }^{3} \&$ Maxim Vladimirovich \\ Savushkin $^{4}$ \\ ${ }^{1}$ Economic and Strategic Development, Kazan (Volga Region) Federal University, Kazan, Russia \\ ${ }^{2}$ Department of Management and Entrepreneurship, Kazan National Research Technological University, Kazan, \\ Russia \\ ${ }^{3}$ Center for Strategic Assessments and Forecasts, Kazan (Volga Region) Federal University, Kazan, Russia \\ ${ }^{4}$ Department of Economics, University of Management “TISBI”, Kazan, Russia \\ Correspondence: Alia Aidarovna Abdukaeva, Center for Strategic Assessments and Forecasts, Kazan (Volga Region) \\ Federal University, Kazan, Russia. Tel: 7-951-064-9504.
}

Received: August 5, 2020

doi:10.5430/ijfr.v11n5p199
Accepted: September 10, 2020

Online Published: October 4, 2020

URL: https://doi.org/10.5430/ijfr.v11n5p199

\begin{abstract}
In the coming years, blockchain technologies may become one of the breakthrough innovations in the financial sector of the economy, optimizing and simplifying transaction operations in a number of areas, and reducing their cost. In this regard, representatives of the financial industry should understand the possible consequences caused by the integration of the technologies under consideration in business processes. It is important to understand that the blockchain technologies have a very significant potential for transforming the established algorithms for the interaction of financial market participants, and be aware where are the boundaries of these changes, what new opportunities are presented by blockchain technologies and. Furthermore, finally, what are the expected consequences for the development of the financial sector itself and the other sectors of the national economic system associated with it. It should be noted that studies on blockchain technologies are very fragmented and, as a rule, have an insufficient level of both theoretical and empirical study. It seems relevant at the present stage of the development of economic science to conduct a systematic study aimed at finding and substantiating the areas of economic activity that are most susceptible to penetration of blockchain technologies. This involves a further justification of the possible consequences and using methods that are not so much qualitative but of quantitative analysis. In this regard, the process of resolving the issues posed in order to minimize risks for financial and other organizations in the face of the opportunities and threats to come under the pressure of the integration of blockchain platforms into the business environment becomes a vital and urgent task. This research is devoted to the solution of the questions posed. Without claiming to be complete and perfect concerning the proposed mechanisms to solve the tasks, the work, in fact, is an invitation to the scientific community to develop further a methodology for studying the influence of blockchain technologies on the dynamics and parameters of the formation of economic growth rates.
\end{abstract}

Keywords: blockchain technology, financial sector, innovation, financial transactions, opportunities and risks, economic growth, the stability of the banking sector

\section{Introduction}

Any technological achievements are aimed at ensuring the growth of competitiveness and the effectiveness of the implementation of the processes in relation to which they were developed. For example, the emerging Internet products in the financial sector have significantly supplanted the traditional transaction procedures at that time.

The economy's financial sector should continuously develop and generate innovations to improve its business processes, cut the cost of financial transactions, maintain and expand its customer base and, ultimately, guarantee the efficiency of financial institutions.

Blockchain technologies and their possible use by financial institutions should undoubtedly be attributed to 
innovations that can transform and modify the clearing and payment processes in corresponding systems, the structure and composition of operational risks in financial institutions and in the insurance sector, maintaining and recording multi-peer databases of financial transactions, etc. (De Meijer, 2016).

Distributed data storage technologies were developed in 2008 by Satoshi Nakamoto to eliminate intermediaries in the data exchange system, including the transition to the scheme of direct exchange of financial assets between their holders (Nakamoto, 2008). To achieve this goal, Nakamoto proposed a peer-to-peer distributed ledger, so a payer and a payee can make an exchange directly over the network using encryption and consensus mechanisms (Guo \& Liang, 2016). Moreover, any changes regarding further operations and transactions between participants in the blockchain platform can be unambiguously detected in the nodes of the blockchain network (Lee \& Lee, 2017; Bahrami, 2018). This property of the technology under consideration is the most important link in any payment system since one of its main goals is protection against double-spending. In other words, the system should be able to track who owns the money and should allow the person who owns the money to spend it only once. Blockchain technology solves the problem of double-spending through a consensus mechanism (Nakamoto, 2008 \& Pazaitis et al., 2017).

Blockchain is a technological innovation that provides an asset exchange process without the need for complete trust between participants in a transaction based on a decentralized accounting system for recording transactions in a more efficient, transparent, and verifiable form (Liebenau \& Elaluf-Calderwood, 2017).

At present, interbank payments very often go through intermediary settlement centers (including clearing houses), thereby forming very complex, laborious, and expensive transaction procedures.

\section{Methods}

The most critical aspect of blockchain systems is that the need for intermediaries will practically disappear, which will accordingly affect the control system of transactions that will be executed according to the peer-to-peer algorithm "a transaction participant" - "a transaction participant" (Figures 1,2).

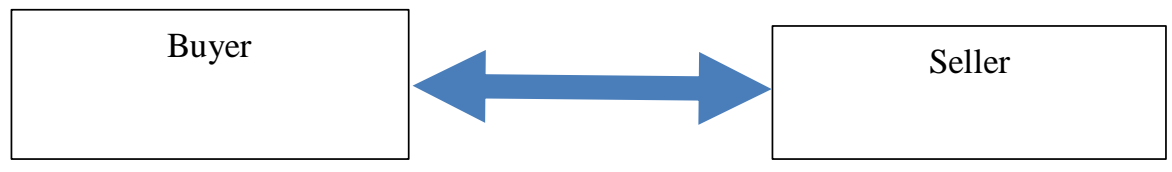

Figure 1. A transaction based on the use of an open blockchain system

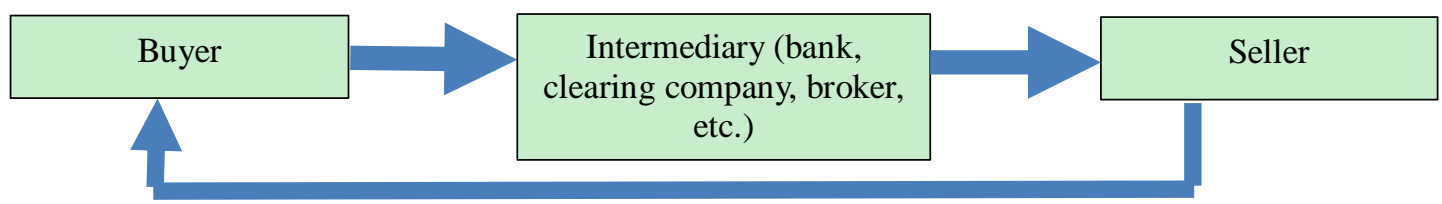

Figure 2. Transaction based on established (traditional) processes and methods for regulating transactions

Blockchain technologies and settlement or payment platforms built on their basis can substantially replace the functionality and purpose of the financial intermediation system. Moreover, these technologies can lead to lower transaction costs and increase the speed of transactions between enterprises and organizations, providing an increase in financial results for business entities. In addition, according to de Meyer (De Meijer, 2016), the use of the technologies under consideration can lead to a reduction in transaction costs (as a result, for example, of a reduction in transaction costs associated with the authentication of trade records for completed transactions) in the securities markets served by banks and exchanges.

Initially, blockchain technology became the basis for cryptocurrency (Bitcoin) circulation. However, it should be noted that the inherent functionality in this technology allows us to solve several applied problems. In this connection, financial institutions, and primarily banks, consider it from the perspective of a tool capable of reducing costs for international payments and trade settlements (Irrera \& Shumaker, 2017) Such expectations of the banking sector of the economy on the introduction of blockchain technologies are capable of revolutionizing the system of financial 
transactions in case of integration of the technologies under consideration in the system of operational processes. According to estimates (Zhao et al., 2016), a possible effect in its revolution can be comparable with the effect that arose when the Internet appeared, which formed the effect of a wide level of information accessibility.

In addition, it should be noted that, in accordance with the position of the same authors (Zhao et al., 2016), the use of blockchain technology can eliminate many known and current problems in the financial services sector: fraud, operational risks, delays in the system of financial transactions and payments. Nevertheless, it is necessary to realize that due to the technological solutions of the blockchain network, when they are significantly scaled, they can work very slowly due to the fact that it takes time to reach consensus on any operation (Tsai et al., 2016).

In general, relying on the above principles and provisions, it should be noted that blockchain technologies have a very high level of potential for optimizing the functioning of the financial system by reducing transaction costs associated with:

- Data accounting and storage;

- Search for information about counterparties;

- Synchronization of heterogeneous information resources;

- Transition to business models with a minimum level of mediation;

- Reduction of risks of financial losses resulting from the use of false information;

- Automation of business processes based on the use of smart contracts;

- Transition to a decentralized procedure for storing and processing data;

- Decrease in the level of financial crime as a result of the invariance of data on completed transactions;

- Reduction of time for processing databases containing dynamically changing information about assets (their owners, value, time of transactions, etc.); and so on.

It should be noted that the financial and real sectors of the Russian economy have already begun to go through the stages of transformation of business processes due to the transition to blockchain technology. In this regard, the search for solutions aimed at moving from general ideas about the impact of blockchain on the economy to formalized assessments with a high level of data and calculation detail to understand the effectiveness and feasibility of transferring the financial transaction infrastructure to the "rails" of blockchain technologies becomes an extremely important task.

The main hypothesis that forms the basis of the author's approach is the position according to which the elimination of fees forms the basis for the release and accumulation of capital of economic entities, which subsequently transforms into an increase in current assets, investments, and increasing business activity. In turn, investment in fixed assets is the most important driver of economic development.

\section{Results and Discussion}

Further, in order to build prognostic assessments of the impact of crypto transactions on the stability and parameters of GDP development, the scenarios of "blocking" the economy and the transition of the financial transaction market to the crypto environment are determined (Table 1). The scale of the transition is due to the need for a comparative analysis of our estimates in terms of the impact on the GDP dynamics with similar estimates published in other studies (Tilooby, 2018 \& Wyman et al., 2015). 
Table 1. Scenario analysis (sensitivity analysis) of adjusting commission income of credit organizations as a result of the transition of the financial system to crypto transactions (compiled according to the Central Bank of the Russian Federation [18])

\begin{tabular}{|c|c|c|c|c|c|c|c|c|c|c|c|c|c|c|}
\hline \multirow[b]{3}{*}{$\begin{array}{l}\text { Total money } \\
\text { transfers as of } \\
01 / 01 / 2019\end{array}$} & \multirow[b]{3}{*}{ 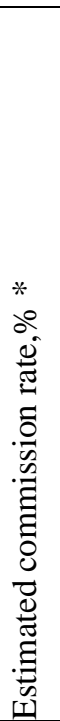 } & \multirow[b]{3}{*}{ 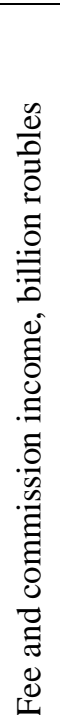 } & \multicolumn{12}{|c|}{$\begin{array}{l}\text { Sensitivity analysis of the reduction in commission income of credit institutions as a } \\
\text { result of a decrease in the "Cash Transfer" indicator by: }\end{array}$} \\
\hline & & & \multicolumn{2}{|c|}{$\begin{array}{l}\text { Scenario 1: } \\
10 \%\end{array}$} & \multicolumn{2}{|c|}{$\begin{array}{l}\text { Scenario 2: } \\
20 \%\end{array}$} & \multicolumn{3}{|c|}{ Scenario 3: $30 \%$} & \multirow[b]{2}{*}{$\begin{array}{l}\tilde{0} \\
. \\
0 \\
0 \\
0 \\
0 \\
0 \\
. \\
0 \\
0 \\
0 \\
0 \\
0 \\
0 \\
0 \\
0 \\
0 \\
0 \\
0 \\
0 \\
0 \\
0\end{array}$} & \multirow[b]{2}{*}{  } & \multicolumn{3}{|c|}{ Scenario 4: $50 \%$} \\
\hline & & &  & 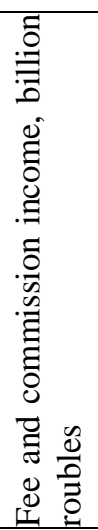 & 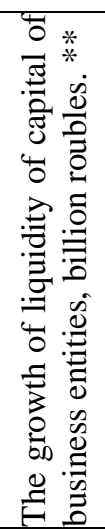 &  & 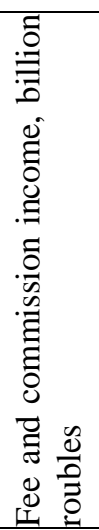 & 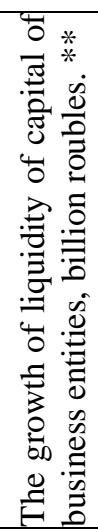 &  & & & 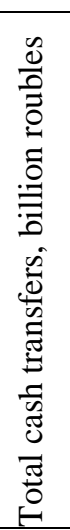 & 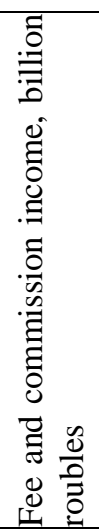 & 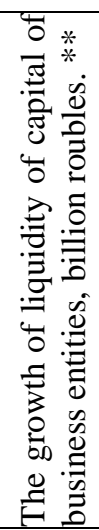 \\
\hline 2 & 3 & $\overline{4}$ & 5 & 6 & 7 & 8 & 9 & 10 & 11 & 12 & 13 & 14 & 15 & 16 \\
\hline 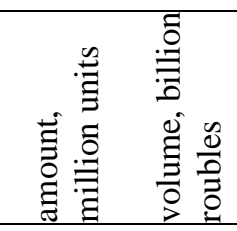 & & & & & & & & & & & & & & \\
\hline 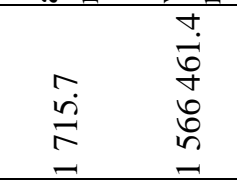 & $\stackrel{8}{\circ}$ & $\begin{array}{l}\infty \\
\stackrel{0}{0} \\
\text { ले }\end{array}$ & $\begin{array}{l}m \\
n \\
\infty \\
8 \\
8 \\
\pm\end{array}$ & $\begin{array}{l}\infty \\
\infty \\
0 \\
\stackrel{0}{1} \\
\end{array}$ & 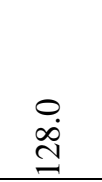 & 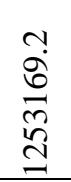 & $\stackrel{a}{\Xi}$ & 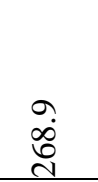 & 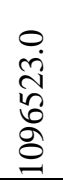 & $\begin{array}{l}\hat{b} \\
\stackrel{0}{\infty}\end{array}$ & oे & $\begin{array}{l}\tilde{0} \\
\tilde{D} \\
\tilde{N} \\
\infty \\
\infty\end{array}$ &  & $\frac{9}{8}$ \\
\hline
\end{tabular}

* The value of the rate is determined by calculation based on the ratio of commission income of credit institutions and the volume of money transfers for the year

** The capital liquidity growth value of economic entities corresponds to a reduction in commission income of credit organizations (For scenario 1, gr. 4 - gr. 6)

Based on the results of the assessments, it can be stated that the capital liquidity growth potential for business entities of the national economy as a result of the transition of the payment system to crypto transactions is from 128 (Scenario 1) to 691.9 (Scenario 4) billion roubles depending on the scale of the transfer of funds to the blockchain system. Considering the low level of the credit organizations income share formed from commission income (about 1\%), it can be stated that the reduction in income under this item is not significant for credit institutions of the financial sector of the Russian economy.

At the same time, the growth of the capitalization of business entities can be of very significant importance directly for both business entities and for the national economy as a whole. Relying on the research algorithm proposed by us, as well as the dependencies obtained below between the level of changes in current assets and the dynamics of GDP (Formula 1), Table 2 presents calculated predictive estimates of the impact caused by the transition of financial transactions to the blockchain environment on the dynamics of GDP.

$$
\mathrm{Y}=20513+0,79 \mathrm{X}
$$


Table 2. Scenario forecast of the GDP growth for the Russian Federation in accordance with the scale of the transition of financial transaction systems to the blockchain system

\begin{tabular}{lllll}
\hline & Scenario 1 & Scenario 2 & Scenario 3 & Scenario 4 \\
\hline GDP growth, in\% & $0,7 \%$ & $2,3 \%$ & $3,9 \%$ & $7,9 \%$ \\
\hline
\end{tabular}

\section{Summary}

The presented estimates demonstrate a very moderate impact of the processes on the dynamics of economic growth, especially in the first scenario. At the same time, it is essential to emphasize that as the volume of crypto transactions increases, and this effect becomes more noticeable. Undoubtedly, in this paper only one "side of the coin" is considered, as we mentioned earlier. Another is related to the risks of financial system stability, transition to a decentralized environment for regulating monetary circulation, etc., and requires separate studies, which will be the subject of the forthcoming works of the authors.

It must be clearly understood that the total deployment of blockchain technologies in the financial environment can lead to unknown consequences, due to insufficient experience in their application in practice (Wyman et al., 2015). In this regard, it is important to determine the spectrum of the processes in the financial sphere, which are the most promising in terms of the functionality of the studied technologies, and to focus all attention on them in the context of the subject of research.

The feasibility of a phased, rather than full-scale deployment of blockchain systems in the financial sector of the economy is due to a number of reasons. These include, for example, the fact that any innovation is fraught with risk, which must be assessed not only within the framework of expert substantiation concerning the implementation of the innovation project, but also give it an assessment based on testing. The most important reason for the phased implementation of blockchain technologies in the activities of financial and other institutions is also associated with the need for a comprehensive understanding of how the use of blockchain will generate economic effects (Mori, 2016).

Given that the development and deployment of the infrastructure of the blockchain system is an expensive process, it is necessary to clearly understand that in the short term the effectiveness of its use can have a negative level. At the same time, like any other investment in the medium and especially in the long term, investment in the systems for optimization of the accounting and the implementation of financial transactions should undoubtedly lead to an increase in economic efficiency for both consumers and blockchain technology developers.

\section{Conclusions}

In conclusion, it should be noted that despite the conflicting approaches and positions of experts regarding the feasibility and possibility of using blockchain technologies in the financial sector of the economy, individual states are already actively moving and developing along the path of implementing blockchain. As a vivid example, we can cite the PRC, where since May 2020 the national cryptocurrency of the Central Bank of China (DCEP) was launched in circulation (Tsai et al., 2016). Since 2020, Chinese banks will use distributed ledger technology to record digital accounts, make payments, and also for other purposes.

It is also important to note that this paper presents one of the possible effects generated as part of the integration of blockchain technologies in the financial sector of the economy. Undoubtedly, when it comes to opportunities, they are not limited to the research aspect studied here. These include the potential to reduce operational and credit risks, minimize disagreements, disputes and claims of transaction participants with each other, increase confidence, etc.

Considering the fact that at the present moment, the study of the impact of blockchain technologies on the parameters of socio-economic development is limited, as a rule, by qualitative assessments within the space of scientific research, this work is in a sense pioneering. In this regard, the issues and methodological approaches disclosed here undoubtedly need further improvement, including within the framework of creating open discussion platforms.

\section{Acknowledgements}

The study was carried out with a grant from the Russian Science Foundation (project No. 19-18-00202).

We express our gratitude to the participants of the scientific project supported by the RFBR No. 18-010-00536 for the help in preparing the paper. 


\section{References}

Bahrami, J. (2018). Marketing and financial issues in Iran. Journal of Management and Accounting Studies, 6(1), 64-72.

De Meijer, C. R. W. (2016). Blockchain and the securities industry: Towards a new ecosystem. Journal of Securities Operations \& Custody, 8(4), 322-329.

Guo, Y., \& Liang, C. (2016). Blockchain application and outlook in the banking industry. Financial Innovation, 2(1), 24.

Irrera, A., \& Shumaker, L. (2017). UPDATE 3-JPMorgan Chase \& Co leaves blockchain consortium R3. Retrieved from http://www.cnbc.com/2017/04/27/reuters-americaupdate-3-jpmorgan-chase-co-leaves-blockchain-consortium-r3.html

Lee, B., \& Lee, J.-H. (2017). Blockchain-based secure firmware update for embedded devices in an Internet of Things environment. The Journal of Supercomputing, 73(3), 1152-1167.

Liebenau, J., \& Elaluf-Calderwood, S. M. (2016). Blockchain Innovation BeyondBitcoin and Banking.

McKinsey. (2016). Blockchain-Disrupting the Rules of the Banking Industry.

Mori, T. (2016). Financial technology: Blockchain and securities settlement. Journal of Securities Operations \& Custody, 8(3), 208-217.

Nakamoto, S. (2008). Bitcoin: A Peer-to-Peer Electronic Cash System.

Pazaitis, A., De Filippi, P., \& Kostakis, V. (2017). Blockchain and value systems in the sharing economy: The illustrative case of Backfeed. Technological Forecasting and Social Change. https://doi.org/10.1016/j.techfore.2017.05.025

Tapscott, D., \& Tapscott, A. (2017). How Blockchain Will Change Organizations. MIT Sloan Management Review, $58(2), 10-13$.

Tilooby, Al. (2018). The Impact of Blockchain Technology on Financial Transactions. Dissertation, Georgia State University. Retrieved from https://scholarworks.gsu.edu/bus_admin_diss/103

Tsai, W.-T., Blower, R., Zhu, Y., \& Yu, L. (2016). A System View of Financial Blockchains. 2016 IEEE Symposium on Service-Oriented System Engineering (SOSE), p. 450.

Wyman, O. R., Group, A., \& Innoventures, S. (2015). The Fintech 2.0 Paper: rebooting financial services. Retrieved from http://santanderinnoventures.com/wpcontent/uploads/2015/06/The-Fintech-2-0-Paper.pdf

Yli-Huumo, J., Ko, D., Choi, S., Park, S., \& Smolander, K. (2016). Where Is Current Research on Blockchain Technology? - A Systematic Review. Plos One, 11(10), e0163477-e0163477. https://doi.org/10.1371/journal.pone.0163477

Zhao, J., Fan, S., \& Yan, J. (2016). Overview of business innovations and research opportunities in blockchain and introduction to the special issue. Financial Innovation, 2(1), 1.

\section{Copyrights}

Copyright for this article is retained by the author(s), with first publication rights granted to the journal.

This is an open-access article distributed under the terms and conditions of the Creative Commons Attribution license (http://creativecommons.org/licenses/by/4.0/). 